자기부상을 적용한 구체 반작용휠 구동기 개발 및 성능 시험

\title{
Development and Performance Test of a Spherical Reaction Wheel Actuator with Magnetic Levitation
}

\author{
김대관 ${ }^{*}$, 윤형주 ${ }^{*}$, 김용복*, 강우용*, 최홍택* \\ Dae-Kwan Kim*, Hyung-Joo Yoon*, Yong-Bok Kim*, Woo-Yong Kang* and Hong-Taek Choi* \\ 요 약
}

새로운 개념의 인공위성 자세제어 작동기에 대한 타당성 연구를 수행하였다. 구체구동기는 단일장치로써 위 성의 3 축 자세제어가 가능한 구동기이며, 구체 플라이휠과 자기부상 및 회전구동을 위한 전자석으로 구성된다. 구체구동기에 대한 수학적 모델링 및 설계를 통하여 시제품을 제작하였으며, 자기부상이 적용된 조건에서 1축 에 대한 구동성능 시험을 수행하였다. 구동성능은 최대속도 7,200 rpm 그리고 최대토크 $0.7 \mathrm{Nm}$ 로 측정되었으며, 속도-토크 특성곡선을 이용한 개루프 속도제어를 통하여 우수한 가속 및 감속 속도제어 결과를 확인하였다. 본 구체구동기는 속도 및 토크 제어를 위한 추가적인 연구를 통하여 성능이 개선될 예정이다.

Abstract

In the present study, a feasibility study on an innovative satellite attitude control actuator is performed. The actuator is specially designed to generate the reaction torque in an arbitrary axis, so that a satellite attitude can be controlled by using itself. It consists of a spherical flywheel and electromagnets for levitation and rotation control of the ball. As the earlier study, a rotating performance test on the spherical actuator is conducted in a single rotating axis and vertical levitation condition. From the test results, it can be confirmed that the maximum speed and torque of the innovative device are 7,200rpm and $0.7 \mathrm{Nm}$, respectively. Using a velocity-voltage characteristic curve of the spherical motor, an open-loop control (V/f constant control) is performed, and the test results show excellent control performance in acceleration and deceleration phases.

Key words : Satellite, Attitude Control, Reaction Wheel, Spherical Actuator, Levitation, Electromagnet

I. 서 론

최근 개발되고 있는 인공위성들은 다양한 임무를 수행하기 위하여 보다 정확한 자세제어와 더불어 더 욱 빠른 기동성능을 필요로 한다. 기존의 자세제어시 스템에서는 정밀자세제어를 위하여 반작용휠(RWA)
이나 제어모멘트자이로 $(\mathrm{CMG})$ 와 같은 구동장치들을 사용하고 있다[1]. 이러한 장치들은 모두 하나의 구 동장치에서 단일 회전축 방향의 제어토크를 발생시 키기 때문에 인공위성의 3축 자세제어를 위해서는 최소한 3개 이상의 구동기 조합을 사용해야 한다. 본 연구의 개발 대상인 구체구동기(Spherical actuator)는

\footnotetext{
* 한국항공우주연구원 위성제어팀(Korea Aerospace Research Institute, Satellite Control System Department.)

· 제1저자 (First Author) : 김대관

· 투고일자 : 2012년 9월 24일

· 심사(수정)일자 : 2012년 9월 24일 (수정일자 : 2012년 10월 19일)

· 게재일자 : 2012년 10월 30일
} 
새로운 개념의 자세제어 작동기로서, 하나의 구체 플 라이휠(spherical flywheel)을 이용하여 임의의 방향으 로 회전이 가능한 구동장치이다. 특히 하나의 구동장 치만으로 3 차원방향의 제어토크 또는 모멘텀을 발생 시킬 수 있으므로 단일장치로써 위성의 3축 자세제 어가 가능하다는 장점이 있다. 따라서 이러한 새로운 개념의 구체구동기를 사용하게 되면 3 개 이상의 조 합을 사용하는 기존의 구동시스템과 비교하여 무게 와 부피의 감소가 가능해지므로 위성의 소형화 및 경 량화가 가능해 진다.

이러한 새로운 형태의 구체구동기에 대한 연구는 아직 까지 몇몇 대학 및 연구소에서만 수행되고 있 다. 특히 국내의 경우 기존형태의 자세제어용 구동장 치인 반작용휠 및 제어모멘트자이로에 대한 연구만 이 대학과 연구원에서 수행되고 있으며, 구체구동기 에 대한 연구는 전무한 상태이다. 외국의 경우 일본 에서 Tokai 대학 및 JAXA에서 2000년 이후 연구를 수행하여 $10 \sim 50 \mathrm{~mm}$ 직경의 구체구동기에 대한 1자 유도 설계 및 시험평가를 수행하였다[2]. 유럽에서는 구체구동기에 대한 연구결과가 발표된 것이 없는 것 으로 파악되지만, 다른 연구목적으로 유사한 연구가 수행된 바가 있다. 스위스의 EPFL 및 ETH에서는 2000 년 이후부터 $1 \sim 4 \mathrm{~mm}$ 직경의 구체에 대한 구동 시험을 수행하여 수백만 RPM의 초고속 회전시험을 수행하였다 [3], [4]. 벨기에 Catholique de Louvain 대 학에서는 2006년도에 2 자유도를 갖는 $50 \mathrm{~mm}$ 직경의 구형 유도 모터를 개발하여 시험평가를 수행하였다 [5].

본 연구에서는 3 축 방향으로 임의의 회전이 가능 한 위성 자세제어용 구체구동기의 개발을 연구목표 로 하고 있다. 현재까지 구체구동기 반작용휠에 대한 제작과 자기부상 조건을 적용한 1축 회전 시험평가 를 수행하였다. 또한 구동성능 결과로 부터 구체구동 기 모터의 속도-토크 특성곡선을 도출하였으며, 이를 활용한 개 루프(open loop) 속도제어 시험을 완료하였 다. 본 논문에서는 한국항공우주연구원에서 개발한 구체구동기에 대한 개발과 주요 시험결과에 대해서 기술하였다.

\section{II. 구체구동기 원리 및 설계}

\section{2-1 구체구동기 작동 원리}

구체구동기의 작동원리는 그림 1 에 나타나 있는 것과 같이 기본적으로 유도모터와 같은 작동원리에 의해서 구동을 하게 된다. 그림에서 보듯이 정지한 구체 주위에 회전하는 자기장이 형성되면, 금속의 구 체표면에 전류가 유도되는데 이를 에디전류 (Eddy current)라고 한다. 이렇게 발생한 유도기전력은 다시 회전자기장과의 상호작용을 통하여 구체 표면에 로 렌츠힘(Lorentz force)을 발생시키게 되고 이는 구체 플라이휠의 회전토크로 작용하게 된다.

만일 구체 플라이휠 주위에 회전하는 자기장의 회 전축이 바뀌게 되더라도 새로운 회전축을 기준으로 유도전류가 발생하게 되므로 여전히 회전자기장과의 상호작용에 의해 회전력이 발생하게 된다. 따라서 회 전자기장의 회전속도와 자기장의 크기 그리고 회전 축 방향 등을 변화시켜 구체 플라이휠을 원하는 방향 과 속도로 회전시킬 수가 있게 된다.

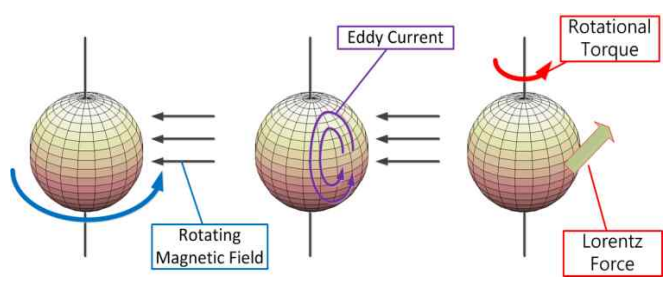

그림 1. 회전 구동 원리 개념도

Fig. 1. Schematic diagram of rotational driving mechanism

\section{2-2 구체구동기 설계}

구체구동기에 대한 설계는 전도체 재료의 구형 플 라이휠에 대한 자기부상 자기장과 회전 자기장 모델 링을 통하여 수행되었으며, 설계에 사용된 회전체 자 기장 모델 및 설계변수 등은 참고문헌[6]을 통해 확 인할 수 있다.

성능해석을 통해 결정된 설계변수들을 기반으로 그림 2와 같이 수직방향으로 자기부상 제어가 가능 한 1 차원 회전용 구체구동기 시제품을 제작하였다. 회전구동은 총 4 개의 전자석에 의해 구현되며, 플라 이휠은 $100 \mathrm{~mm}$ 직경의 중공타입으로서, 철 층과 구리 
층의 2중 구조를 가지며, 질량 및 관성 모멘트는 각 각 $\mathrm{m}=3.448 \mathrm{Kg}$ 과 $\mathrm{I}=0.0042 \mathrm{Kg} \cdot \mathrm{m} 2$ 이다.

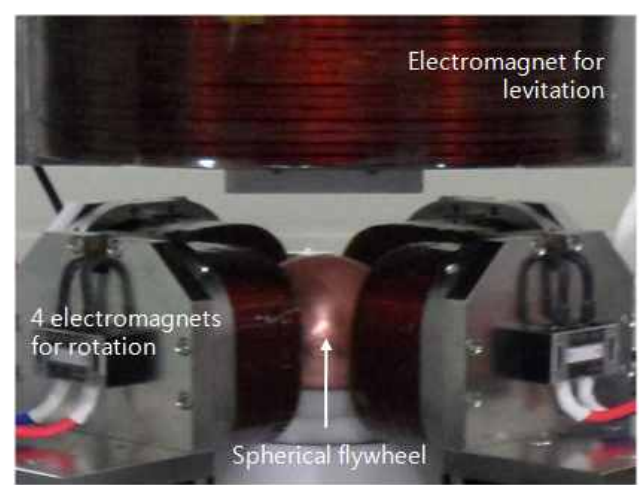

그림 2. 자기부상 조건의 구체 반작용휠 구동기

Fig. 2. Spherical reaction wheel actuator under magnetic levitation system

\section{III. 구체구동기 성능시험 및 평가}

\section{3-1 성능시험 시스템}

구체구동기의 구동시험을 위한 시험평가 시스템 은 그림 3과 같이 구동기와 제어 장치로 구성된다. 구동기(Spherical Reaction Wheel)는 자기부상을 위한 1 개의 수직방향 전자석과 회전 자기장 발생을 위한 4개의 수평방향 전자석 그리고 구형의 플라이휠로 구성된다. 제어 장치(SRW Control System)는 전자석 구동용 드라이버와 속도 측정을 위한 타코미터 (tachometer) 그리고 자기부상 및 회전구동 제어와 속 도 측정을 위한 실시간 RTI/DAQ 장비로 구성되며, 세부사항 정보는 표 1과 같다.

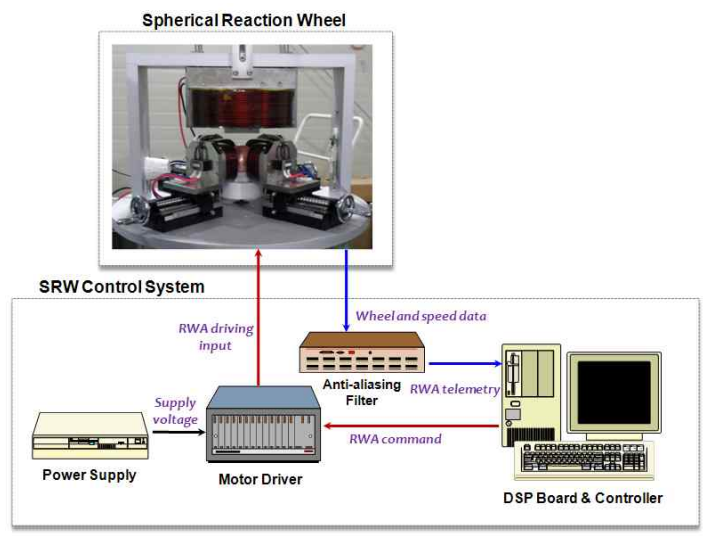

그림 3. 시험장치 개념도

Fig. 3. Schematic diagram of test system
표 1. 시험장치 세부 정보

Table 1. Test equipment specification

\begin{tabular}{c|l}
\hline \hline Equipment & \multicolumn{1}{|c}{ Specification } \\
\hline \multirow{3}{*}{ RTI/DAQ } & - Model: dSPACE-1103 (fs = 2024 Hz) \\
& - Input: tacho-pulse, PWM volt \& current \\
& - Output: driving frequency, phase, PWM \\
\hline \multirow{3}{*}{ Driver } & - Model: electromagnet driver \\
& - Levitation input: DC control power \\
& - Rotation input: frequency, Amplitude, \\
& phase (PWM1 and PWM2) \\
\hline \multirow{3}{*}{ Tachometer } & - Model: ACT-3X \\
& - RPM range: 5 999,990rpm \\
& - Pulse output: $+5 \mathrm{~V}$ \\
\hline \hline
\end{tabular}

\section{3-2 성능 시험}

구체구동기의 성능 측정 시험은 자기부상 전자석 을 이용하여 구체 플라이휠을 수직방향으로 부상시 킨 상태에서 수평방향의 회전구동 전자석을 이용하 여 회전시키며, 측면 방향에 설치된 타코미터를 이용 하여 속도를 측정하는 방식으로 수행되었다.

구체구동기 성능시험의 각 시험조건에서 적용된 입력변수 값들은 표 2에 정리하였다. 모든 구동시험 은 플라이휠이 정지된 상태에서 고정된 $\mathrm{PWM}$ 의 크기 (A)와 주파수(f)를 인가하여 최대 속도에 이르기까지 가속시키면서 속도를 측정하였다. 이러한 성능시험 은 아래와 같이 총 41 개의 시험조건에 대해서 수행되 었다.

표 2. 성능시험 입력 변수 및 시험조건

Table 2. Input parameter and test condition for performance test

\begin{tabular}{c|c}
\hline \hline Parameter & Input value \\
\hline PWM Phase & $-90 \mathrm{deg}$ for all test cases \\
\hline $\begin{array}{c}\text { Rotation } \\
\text { Frequency(f) }\end{array}$ & $-20 \mathrm{~Hz}, 30 \mathrm{~Hz}, 40 \mathrm{~Hz}, 50 \mathrm{~Hz}, 60 \mathrm{~Hz}$ \\
\hline & $-30 \mathrm{~V} \sim 120 \mathrm{~V}$ for $20 \mathrm{~Hz}(7 \mathrm{set})$ \\
PWM & $-30 \mathrm{~V} \sim 120 \mathrm{~V}$ for $30 \mathrm{~Hz}(7 \mathrm{set})$ \\
Amplitude(A) & $-45 \mathrm{~V} \sim 150 \mathrm{~V}$ for $40 \mathrm{~Hz}$ (8set) \\
& $-90 \mathrm{~V} \sim 150 \mathrm{~V}$ for $50 \mathrm{~Hz}(11 \mathrm{set})$ \\
\hline Total test case & $41 \mathrm{set}$ \\
\hline \hline
\end{tabular}




\section{3-3 속도 측정 및 토크 계산}

구체구동기의 성능시험을 통해서 측정된 타코신 호를 이용한 속도 검출방법에는 대표적으로 펄스카 운트 방식(M-method)과 샘플링 방식(T-method)이 사 용된다. 본 시험에서는 샘플링 방식을 적용하여 속도 를 측정하였다. 샘플링 방식은 속도 데이터의 샘플링 이 일정하지 않고, 데이터에 잡음이 발생하며, 또한 저속 영역에서 데이터가 충분하지 않다는 문제점이 있다. 특히, 이러한 속도 오차들은 속도 데이터의 미 분을 통해 계산되는 회전 가속도에 매우 큰 오차를 발생시키는 원인이 된다. 본 연구에서는 구체구동기 의 성능분석을 위하여, 연속적인 속도 함수를 이용하 여 속도 데이터를 추정하였으며, 추정된 속도 함수의 미분을 통하여 회전 토크를 계산하였다.

구체구동기 성능시험의 속도 데이터 특성은 그림 4 와 같이 연속적인 2 개의 함수 $\left(f_{1}\right.$ 과 $\left.f_{2}\right)$ 와 상수 (constant)로 구성된다고 가정되었다. 여기서 함수 $f_{1}$ 과 $f_{2}$ 는 다음과 같이 각각 $\mathrm{m}$ 차와 $\mathrm{n}$ 차의 다항식으로 표현될 수 있다.

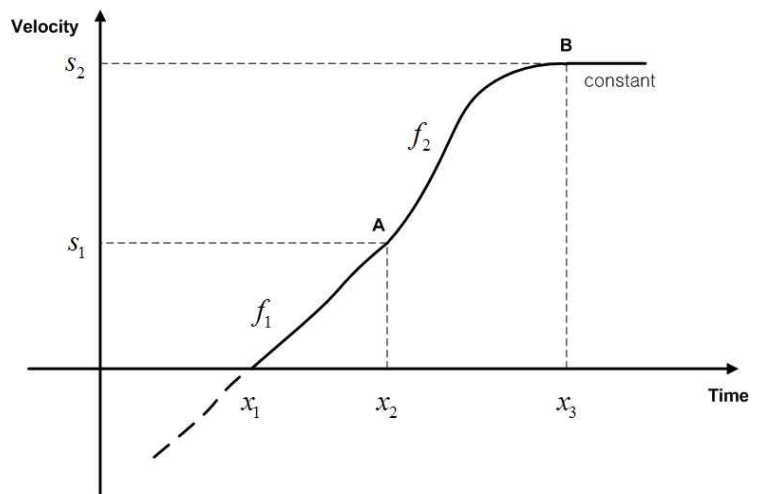

그림 4. 구체 반작용휠의 속도 곡선

Fig. 4. Velocity curve of spherical reaction wheel

$$
\begin{gathered}
f_{1}(x)=A_{1} x^{m}+A_{2} X^{m-1}+\cdots+A_{m+1} \\
f_{2}(x)=B_{1} x^{n}+B_{2} X^{n-1}+\cdots+A_{n+1}
\end{gathered}
$$

두 함수에 대한 연속 조석은 아래의 접합 방정식 을 통하여 보장될 수 있다.

$$
\begin{aligned}
& f_{1}\left(x_{2}\right)=f_{2}\left(x_{2}\right), f_{2}\left(x_{3}\right)=s_{2}, f_{2}{ }^{\prime}\left(x_{3}\right)=0, \\
& f_{1}^{\prime}\left(x_{2}\right)=f_{2}{ }^{\prime}\left(x_{2}\right), f_{1}{ }^{\prime \prime}\left(x_{2}\right)=f_{2}{ }^{\prime \prime}\left(x_{2}\right)
\end{aligned}
$$

본 연구에서는 $m=3, n=4$ 를 적용하였으며, 전체 변수는 9 개의 함수 계수와 두 함수의 접점위치 $x_{2}$, 함수와 상수의 접점위치 $x_{3}$, 상수 값 $s_{2}$ 가 된 다. 식(3)의 접합 방정식을 적용하면 최종적으로 7개 의 미지수가 존재하게 된다. 이러한 미지수들은 속도 함수와 측정된 속도 데이터를 이용한 곡선 접합 방식 으로 결정될 수 있으며, 이를 위하여 Maltab의 최적 화 툴인 "fminsearch"함수를 사용하였다. 이러한 최적 화 방식으로 추정된 속도 모델은 그림 5 와 같이 실제 측정데이터와 일치하는 결과를 보이고 있으며, 추정 된 속도 함수의 미분을 통하여 그림 6과 같이 회전속 도에 따른 가속도를 계산할 수 있다.

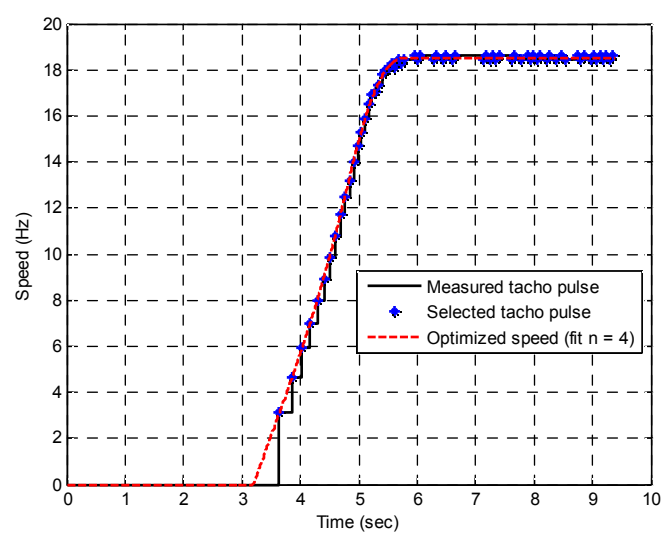

그림 5. 회전 속도 데이터 $(f=20 \mathrm{~Hz}, A=75 \mathrm{~V})$ Fig. 5. Rotation speed data $(f=20 \mathrm{~Hz}, A=75 \mathrm{~V})$

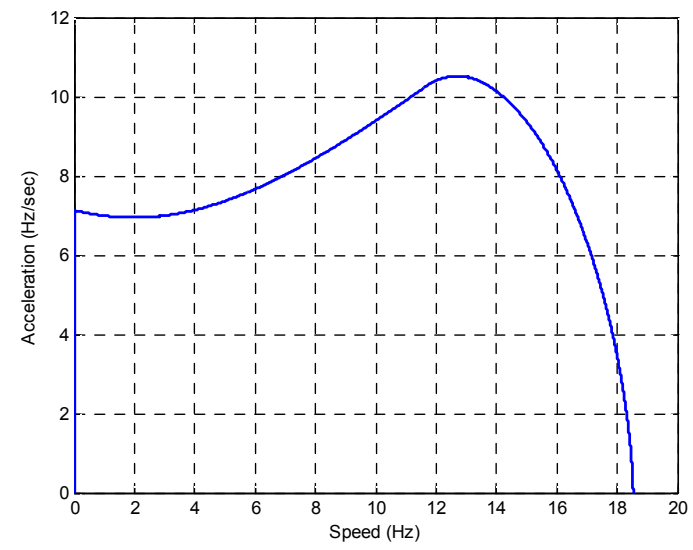

그림 6. 회전 가속도 데이터 $(f=20 \mathrm{~Hz}, A=75 \mathrm{~V})$

Fig. 6. Acceleration data $(f=20 \mathrm{~Hz}, A=75 \mathrm{~V})$ 


\section{3-4 성능 평가}

구체구동기 성능 시험으로부터 측정된 타코 신호 에 대한 속도 함수화를 통하여, 각 시험조건에 대한 토크를 계산하였으며, PWM의 구동 주파수(f)에 따른 토크결과는 그림 7과 같다.

일정한 구동 주파수에서 PWM의 크기에 따라 토 크가 증가되며, 각 구동 주파수에 대한 슬립(slip)은 $\mathrm{PWM}$ 의 크기의 증가에 따라 감소함을 보이고 있다. 최대 토크는 그림 8 과 같이 약 $0.7 \mathrm{Nm}$ 로서 $50 \mathrm{~Hz}$ 까지 유지되며, 그 이상의 주파수에서 감소함을 확인할 수 있다. 이러한 속도-토크 특성은 전형적인 유도전동기 의 구동특성과 일치하는 결과이다.

본 연구에서 개발된 구체구동기는 무부하 조건에 서 구동되며, 최대 토크가 정격토크의 약 $175 \%$ 가 되 도록 가정하여 $50 \mathrm{~Hz}$ 의 정격주파수와 $0.4 \mathrm{Nm}$ 의 정격 토크를 구동조건으로 결정하였다.
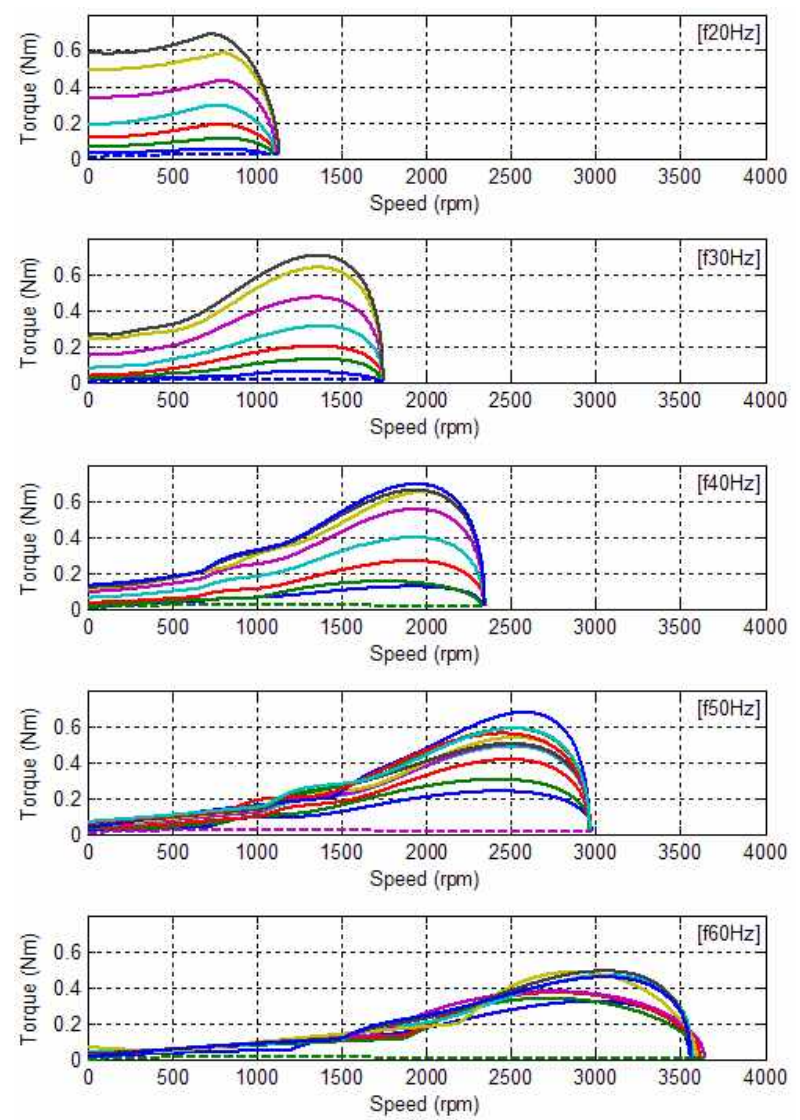

그림 7. 속도-회전토크 곡선

Fig. 7. Speed vs. rotation torque curves

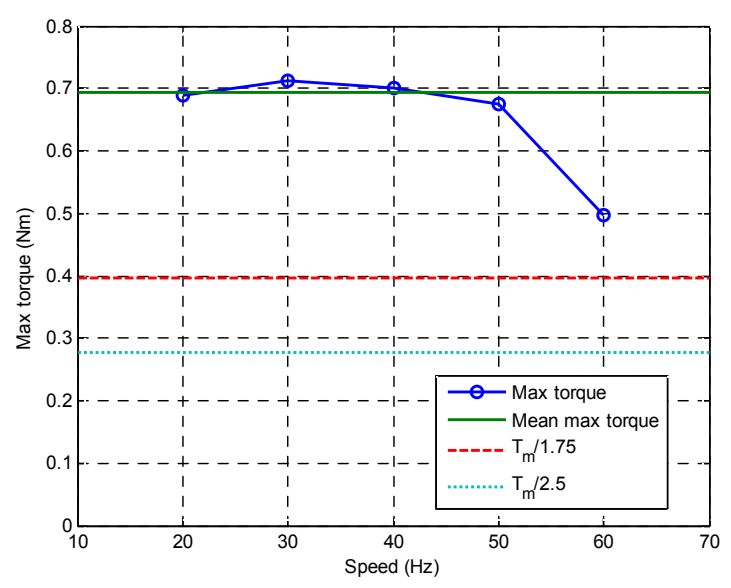

그림 8. 최대 토크 곡선

Fig. 8. Maximum torque curve

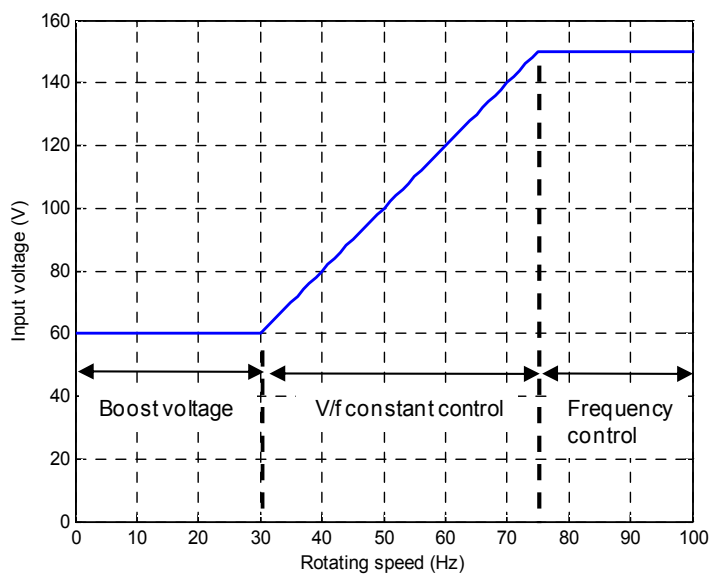

그림 9. $V / f$ 일정제어 입력 전압 곡선

Fig. 9. Input voltage curve for $\mathrm{V} / \mathrm{f}$ constant control

\section{IV. 개루프 속도 제어}

유도전동기의 속도 제어법에는 크게 평균토크를 제어하는 스칼라제어와 순시토크를 제어하는 벡터제 어로 구분할 수 있다[7]. 본 연구에서는 위치센서가 필요하지 않고 제어가 단순하여 적용하기 쉬운 스칼 라제어를 적용하였으며, 특히 속도제어범위가 넓고 효율이 높아서 가장 광범위하게 사용되고 있는 V/f일 정제어를 사용하였다.

구체구동기의 정격 구동조건으로부터 $\mathrm{V} / \mathrm{f}$ 일정제 어 전압이득을 $\mathrm{V} / \mathrm{f}=2.0$ 으로 결정하였다. 이렇게 정 해진 제어조건은 그림 9 와 같이 주파수 영역에 따라 서 3 개의 구동영역으로 구분하여 적용되었다. $0 \sim 30 \mathrm{~Hz}$ 까지는 저속 구동 구간으로서 초기 기동 
을 가속화시키기 위한 Boost 전압제어가 적용되며, $30 \sim 75 \mathrm{~Hz}$ 까지는 속도명령에 비례하여 전압명령 이 생성되는 $\mathrm{V} / \mathrm{f}$ 일정제어가 적용되며, $75 \mathrm{~Hz}$ 이상에 서는 구체구동기의 최대 구동전압 $(150 \mathrm{~V})$ 에 해당하는 제한영역으로서 주파수제어가 적용된다. 이러한 속 도-전압 이득 곡선을 적용하여 구체구동기 1축에 대 한 개루프(open-loop) 속도 제어를 수행하였다.

본 연구에서 수행된 개루프 구동제어는 $10 \sim 40 \mathrm{~Hz}$ 에 해당하는 다중 스텝 명령에 대해 수행되었다. 이 중 $20 \mathrm{~Hz}$ 와 $30 \mathrm{~Hz}$ 의 다중 스텝 명령에 대한 개루프 제 어 응답은 그림 10 에 나타나 있다. 각 스텝에 대해서 작은 슬립에 의한 오차가 존재하며, 모든 가진 주파 수 영역에 대해서 속도명령과 잘 일치함을 확인하였 다. 또한 최대속도는 $120 \mathrm{~Hz}(7,200 \mathrm{rpm})$ 까지 측정되었 다. 특히, 회생제동을 통해 구현되는 감속 구간의 속 도제어는 가속구간의 속도제어보다 빠른 응답반응을 보이고 있다. 이러한 회생제동 특성 또한 유도전동기 의 일반적 특성과 일치하는 결과이다.
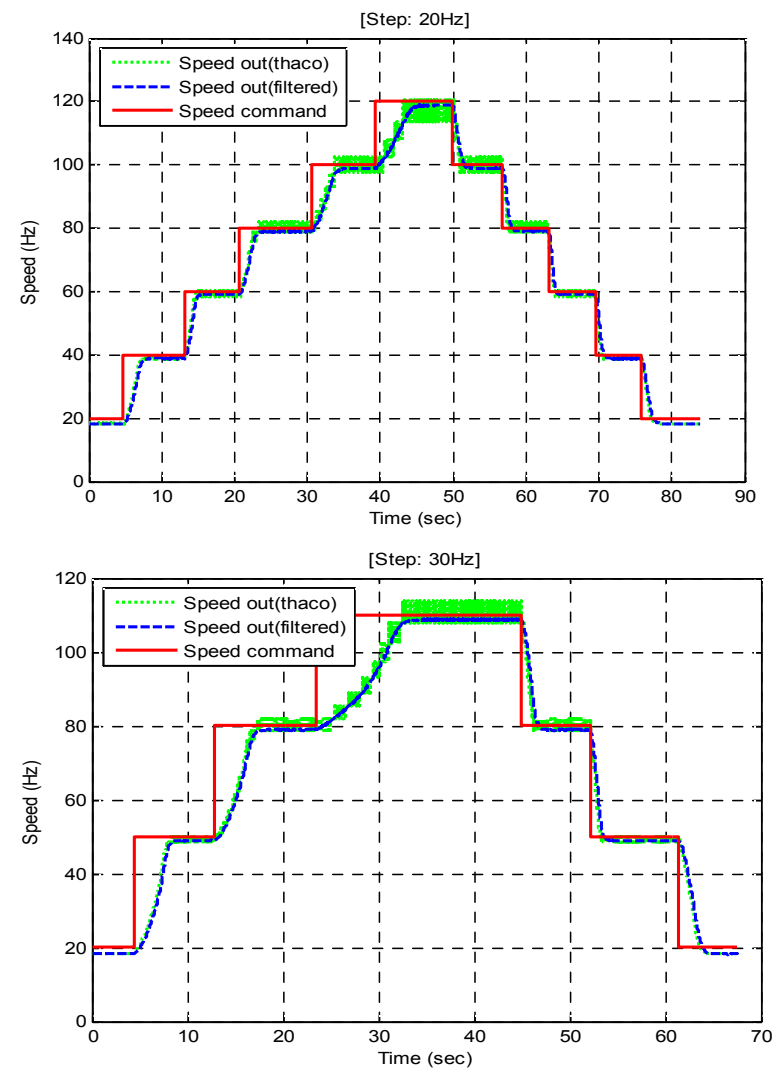

그림 10. 다중 스텝 응답 곡선 $(20 \mathrm{~Hz}, 30 \mathrm{~Hz}$ input $)$

Fig. 9. Multiple step responses $(20 \mathrm{~Hz}, 30 \mathrm{~Hz}$ input)
본 연구에서 확인된 구체구동기의 최대 토크 $(0.7 \mathrm{Nm})$ 및 최대속도 $(7,200 \mathrm{rpm})$ 는 기존 상용위성들에 서 사용되고 있는 반작용휠의 최대 토크영역(0.01 $2 \mathrm{Nm})$ 과 최대 속도영역(600 6,000rpm)에 부합되는 결과이며, 해외에서 수행된 유사한 연구[2]의 최대속 도 보다 6배 이상의 최대 회전속도를 갖는 결과이다.

\section{$\mathrm{V}$. 결 론}

본 연구에서는 새로운 형태의 자세제어용 구동장 치인 구체구동기에 대한 설계 및 성능평가를 수행하 였다. 자기부상 및 1 축 회전이 가능한 구체구동기에 대한 설계 및 시제품 제작을 수행하였으며, 1축 회전 에 대한 구동성능 시험과 속도제어를 수행하였다. 특 히, 측정된 타코 데이터에 대한 속도 함수화를 적용 하여 회전토크 계산과 구동성능 특성을 도출하였다. 현재까지 구체구동기의 최대속도는 7,200 rpm이며, 최대토크는 $0.7 \mathrm{Nm}$ 로 측정되었다. 또한 속도-토크 성 능특성 그래프로부터 속도-전압 이득을 결정하여 개 루프 속도제어를 수행하였으며, 명령 속도에 대해서 가속 및 감속을 통한 속도제어가 성공적으로 이뤄졌 음을 확인하였다. 이러한 성능결과는 상용 반작용휠 의 성능에 근접하는 결과이며, 구체구동기와 관련된 국외연구 사례에 비해 우수한 결과라고 판단된다. 본 구체구동기는 패루프(closed-loop) 속도 제어 및 3 차 원 회전구동 등의 후속연구를 통하여 추가적인 성능 개선이 이뤄질 예정이다.

\section{참 고 문 헌}

[1] 김대관, 오시환, 이선호, 용기력, "반작용휠의 미소 진동 측정법에 관한 실험적 연구," 한국소음진동 공학회논문집, 제 21권, 제 9호, pp. 828 833, 2011.

[2] Iwakura, A., Tsuda S. and Tsuda T, "Feasibility Study on Three Dimensional Reaction Wheel," Proceedings of the School of Science of Tokai University, Series E, Vol.33, pp.51 57, 2008.

[3] Boletis, A., Sache, L., Menot, S. and Bleuler, H., 
"Magnetic Levitation and Rotation of Sub-millimetric

Spherical Rotors," International Conference on Magnetically Levitated Systems and Linear Drives (MAGLEV2002), Lausanne, Switzerland.2002.

[4] Wildmann, C., Nussbaumer, T. and Kolar, J. W., "10 Mrpm Spinning Ball Motor - Preparing the next generation of ultra-high speed drive systems," International Power Electronics Conference, 2010.

[5] Dehez, B., Galary, G., Grenier, D. and Raucent, B., "Development of a Spherical Induction Motor With Two Degrees of Freedom," IEEE TRANSACTIONS ON MAGNETICS, VOL.42, NO.8, pp.2077 2089, 2006.

[6] Park, G., Yoon, H., Kim, D. K., Yong, K. L. and Sergei,

E., "Feasibility Study and System Conceptual Design for the Spherical Actuator," 11th International Conference on Control, Automation and Systems, Oct. 26 29, KINTEX, Korea, pp. 1875 1879, 2011. [7] 이주, "전기기기", 홍릉과학출판사, 2011.

\section{김 대 관 (金大寬)}

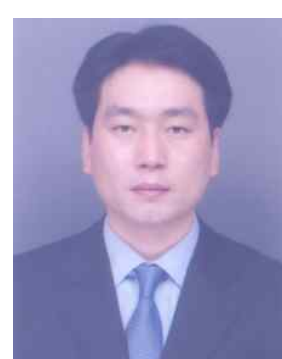

2001년 2월 : 한국항공대학교 항공 기계공학과(공학사)

2003년 8월 : 한국과학기술원 항공 우주공학과(공학석사)

2008년 2월 : 한국과학기술원 항공 우주공학과(공학박사)

2007년 12월현재 : 한국항공우주연구원

위성제어팀 선임연구원

관심분야 : 자세제어, 미소진동, 영상지터, 진동제어

\section{윤 형 주 (尹畑柱)}

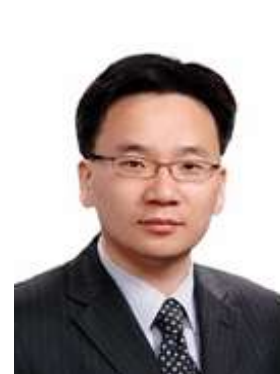

1994년 2월 : 한국과학기술원 항공 우주공학과(공학사)

1996년 2월 : 한국과학기술원 항공 우주공학과(공학석사)

2004년 12월 : Georgia Tech, Aerospace

Engineering(공학박사)

2010년 2월 현재 : 한국항공우주연구원

위성제어팀 선임연구원

관심분야 : 자세제어, 지터제어, 제어 모멘트 자이로(CMG)

\section{김 용 복 (金容福)}

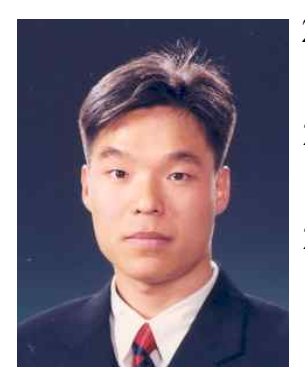

2001년 2월 : 연세대학교 전기공학과 (공학사)

2003년 2월 : 서울대학교 전기컴퓨터 공학부(공학석사)

2003년 3월 현재 : 한국항공우주연구원 위성제어팀 선임연구원

관심분야 : 구동기제어, RTOS 구동장치

\section{강 우 용 (姜右勇)}

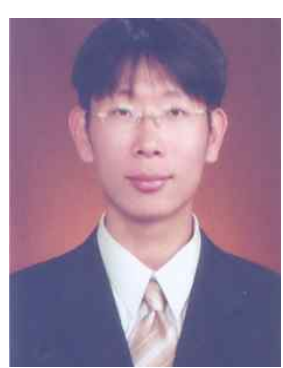

2004년 2월 : 부산대학교 전자공학과 (공학사)

2006년 2월 : 서울대학교 기계항공 공학부(공학석사)

2006년 2월 2007년 7월 : 현대자동차 연구원

2007년 7월 현재 : 한국항공우주연구원

위성제어팀 선임연구원

관심분야 :위성제어, 관성항법

\section{최 홍 택 (崔洪澤)}

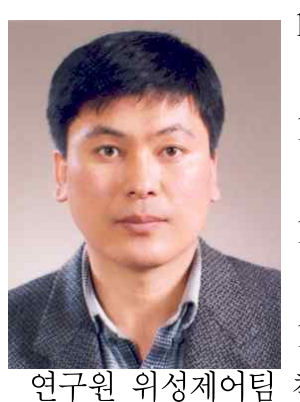

1982년 2월 : 한양대학교 기계공학과 (공학사)

1991년 6월 : University of Idaho, Mechanical Engineering(공학석사) 1994년 6월 : University of Idaho, Mechanical Engineering(공학박사) 1994년 10월 현재 : 한국항공우주

관심분야 : 자세제어, 진동제어 